\title{
Study on Optimizing the Value Chain of Tourism Electronic Commerce
}

\author{
Li Wei, Xue Bin, Song Hongyan \\ Hengshui University, Hbei, Hengshui053000 \\ hunter2011@foxmail.com
}

Keywords: Tourism electronic commerce, Value chain, Value link, Optimizing of value chain.

\begin{abstract}
With the development of the tourism electronic commerceat top speed and its situation in economy and trade it has been presented gradually. The developed country has to pay attention to the newly developing international market of tourism electronic commerce. It can improve international competitive power of tourism electronic commerce in our country through optimizing the value chain of tourism electronic commerce in our country. We make the mathematical statistics method be cited into the optimizing analysis of tourism electronic commerce, and firstly we use the method of comparative analysis to provide the strategy of long-term optimizing of the value chain of tourism electronic commerce with theoretical basis, and then we use the model and mathematical statistics method to provide the strategy of short-term optimizing of the value chain of tourism electronic commerce with practical basis. We combine the theory with the demonstration and long-term strategy and short-term strategy to provide the optimizing of tourism electronic commerce in our country with some specific and feasible suggests.
\end{abstract}

\section{Introduction}

On the era background of network information, whatever industry can not keep them out of network, and the tourism is also no exception. They can not protect themselves for their own survival and development if they do not keep close connection with the network. Tourism is an industry information-intensive and information-based, and the features of network information industry are high-efficient in information search, inquiring and integration. Tourism electronic commerce must be the prospective development direction of tourism, and it has enormous potential to develop.

The contribution rate of tourism in domestic commerce and service trade has increased step by step. In addition, the tourism electronic commerce must be the prospective development direction of tourism. Therefore, it has important strategic significance for the economic development in our country which promots the international competitive power of tourism electronic commerce in our country.

\section{The Composition of Value Chain of Tourism Electronic Commerce}

The different scholars have different definitions on the tourism electronic commerce. In the Theory and Practice of Tourism Electronic Commerce written by Wuning and Yang Luming, the definition of tourism electronic commerce is shown as follows. The tourism electronic commerce refers to we can realize the electronization of various links of tourism commerce activity through advanced methods of network information skill ${ }^{[3]}$. In the book of Tourism Electronic Commerce written by Dimitros Buhalis and translated by some persons like Ma Xiaoqiu, the tourism electronic commerce has been described as the electronic travel, and we can give it a definition of 'the dynamic bonding of information and communication technology and tourism, ${ }^{, 4]}$. In this book, the electronic travel is a bonding of three aspects, and that is to say, they are enterprise management, tourism and information as well as its management.

Although the different scholars have different definitions on the tourism electronic commerce, but the essence of tourism definition of value chain defined by them is similar. The definition of value chain about tourism industry can be summarized into two aspects: For one aspect, the value chain of tourism is mainly a value chain of industry, which consists of supplier, agent and consumer 
of tourism; and for another aspect, this value chain reflects the relationship of a chain of supply and demand beween the interior and the exterior of tourism industry.

\section{Optimizing the Value Chain of Tourism Electronic Commerce in Our Country}

The Long-Term Strategy about what Optimizing the Value Chain of Tourism Electronic in Our Country. According to the problems of value chain of tourism electronic commerce in our country described above, the long-term strategy about what optimizing the value chain of tourism electronic in our country has several points below.

(1) Tourist. In the value chain of tourism electronic commerce in our country, the first we should do in the link of tourist is to give much attention on the value of tourist, and the second is to make the explicitness of value which has been neglected before be included in the value of value chain of tourism electronic commerce. During the process of tourism electronic commerce in our country, the tourist consumer has very crucial value significance for the value chain of tourism, and this value and significance mainly presente that if the tourism consumers have very good experience they can play a very important publicity function for the tourism products. And they can design new tourism products, and provide the supplier of tourism service with the reference to further safisfy the tourist's request.

(2) Travel Agency. It is much-needed for the travel agency to release personalization product marketing. In online marketing, the travel agency can not grasp the market shares referred to in the theory of ' Long Tail Theory', if they still adopt the simple method of 'attractions + transport + restaurant= tourist route', or entirely adopt the marketing strategy of ' one to many'. Thus, they will lose the customer resources which they can use before and the chance of appreciation.

We should translate simple counsel into diversified service, and take providing guide service as appreciation point. The travel agency can not just make the answer of information, but should mainly do newly integration and newly package to create an international brand. In the meanwhile, the travel agency should give play to the advantages of their own guiding business, and establish the flexible guiding business for contenting personal request of travel business in various travel groups.

We should establish the completed credibility mechanism, the trust problem in online transaction of traveling has been more prominent, because the environment of virtual online transaction at present has a hug risk and uncertainty. In online travel booking, such as the security of the user's personal information, the password of bank account, and some questions like whether the commitment of travel agency will become true after paying, and all of these are the consumer's concerns.

(3) Transport and Restaurant. We should strength the issuing of network information, and promote the value of publicity. The travel agency should issue the information of restaurant's exterior environment and room decoration on the website in time to attract the consumer's attention.

We should fully use the network to strength the consumer's bond, to clear up the document of visiting consumer for deep exploration, to remain the connection with consumer by e-mail for the consumers to learn discounted information in time. We should complete the online book system, and implement fixing a price by balance. For example, surrendering part of the profits aims at last room or last air ticket.

We should open the online evaluation system, take a compensation to the consumer as a reward for their evaluation. We should fully use the creation value and the publicity value of the consumers in products.

We should strength the connection with various links of tourism electronic commerce, and pay much attention on the products areas which overlap with other products areas. We should release the products by combination over the intersection area for avoiding the vicious competition in price.

The Short-Term Strategy to Optimizing Value Chain of Tourism Electronic Commerce of Our Country.

(1) Tourist-- Translate to Travel Habit Step by Step, Using Reasonable Way to Travel. The methods for the tourist use to travel can impact on the value chain of tourism electronic commerce at a large degree, that is to say, when many people are keen on that taking the capital flow and 
taking the information communication on the network, the appreciation of the value chain of tourism electronic commerce will benefit from the methods of traveling online. At the same time, other links should take discounted activities to attract the tourist to take more reasonable method to travel, to lay a good foundation for optimizing the value chain of tourism electronic commerce.

(2) Travel Agency-- To Rightly Orient Targeted Consumer to Decline Unuseful Consumption and Increase Value. The travel agency can decline the unuseful consumption at a maximum degree so that they can greatly reduce the cost of traveling service if the travel agency accurately orients the targeted clients in the process of specific travel service. At present, the travel agency should try every means to commence the conversion of their role, and should be serious to carry out the establishment of network platform, and should exert itself to promote its service ability and level on the network, and to improve the efficiency level of travel agency operation.

(3) Transport and Restaurant-- To Further Improve and Perfect Information Platform. The tourism consumers should pay their attention especially to whether they can book restaurants and learn the situation of transport on the network platform, and whether the consumers can save more time cost if they book the restaurants on the network. In the meanwhile, the room price can impact on the consumption of tourist if the price is too high, because most of tourism consumers put the emphasis on the room price. Thus, the restaurant should find a proper balance point between the price and the number of people.

(4) The Supplier of Destination-- To Exert Themselves to Electronic Brochure, and Establish Book Ticket System. At present, the tourists think the most important thing is to perfect the destination electronic brochure for promoting value. As far as most of suppliers of destination are concerned, especially the suppliers with small size, they can exert themselves to enrich the publicity function of destination website. For example, the electronic brochure is available for the download, and the scenic spots is available for play and so on. Secondly, because the online booking ranks only second to the publicity in optimizing. Therefore, in order to realize the appreciation of value, the suppliers of destination should project the construction of booking tickets function actively, and fight for the government's support in the meantime.

(5) The Platform of Tourism Electronic Commerce-- To Perfect B2C, and to Normalize C2C to Further Recall the Creation Space of Value. Perfecting B2C platform to enlarge its value space presents two aspects. One is that the tourist can choose the travel agency in other places to sign up for travel through this platform to get more signified travel price. The other one is that the platform should open up the function of 'paying and evaluation after traveling' to let the consumers hold more initiative. For example, the consumers could purchase the travel route through the procedure like buying on the website of Taobao. In other words, the consumer paid the money to Taobao before, and after the travel Taobao could give the money to the travel agency if the consumer felt satisfied, or the consumer could apply for discount or mediate if they felt dissatisfied.

(6) The Whole of the Value Chain of Tourism Electronic Commerce. As shown in the analysis result, the platform of tourism electronic commerce has the most significant influence on the value chain, but the weight of travel agency is low comparatively. And this happens to have the coincidence with the analysis of various links of value chain of tourism electronic commerce in the beginning of this paper. In the previous analysis, no matter which link takes the value activity, it needs the platform of tourism electronic commerce. We may think that the platform of tourism electronic commerce participates in all of value activities, so it has the significant influence on the value chain relatively. But all of the activities travel agency participate in are determined by the travel method of tourists. And its activity section is narrow relatively. Thus, its influence is much little relatively. Therefore, in terms of optimizing the value chain of tourism electronic commerce, the priority is to start with the platform of tourism electronic commerce, and the value appreciation of other links can only be improved if establish good platform of tourism electronic commerce firstly. 


\section{Conclusion}

We take the value chain of tourism electronic commerce in our country for example to analyze and optimize the value chain of tourism electronic commerce in our country by the method of optimizing in theory, and to obtain the long-term strategy optimizing the value chain of tourism electronic commerce in our country through correlation method, and to obtain the short-term strategy of the value chain of tourism electronic commerce in our country through analyzing the data of questionnaire. As far as the tourists are concerned, the government and other links should put the emphasis on the method which the tourists participate in the travel so as to conduct the tourists. As far as destination suppliers are concerned, the destination suppliers should exert themselves to perfect the online products especially to realize the selling of online ticket booking with the support of government. As far as restaurant and transport are concerned, it should fully use the online distribution channels to realize the diversification in price, to advance the use rate of resources. As far as travel agency is concerned, it should integrate with the international online service to lock the targeted clients and provide them with pertinence and personality service.As far as the platform of tourism electronic commerce is concerned, it should put emphasis on the construction of the platform of $\mathrm{B} 2 \mathrm{C}$, the $\mathrm{C} 2 \mathrm{C}$ to safisfy the request of online service of tourists. As far as the whole of platform of tourism electronic commerce is concerned, the platform of tourism electronic commerce should play an important role in the tourism, and this also verifies the crucial role of the platform of tourism electronic commerce presented in the theory analysis.

\section{References}

[1] F. Zhou. The Economics Analysis of Tourism Electronic Commerce. Commercial Age, 2010(19).

[2] C.L. Zhou, J. Yang, Z.Y. Yu. Delivery Assessment and its Evaluation Study of Content Delivery Performance of Travel Electronic Commerce Website. Academic Journal of Tourism, 2010(12).

[3] J. Kang. The Exploration and Discussion on Electronic Commerce of Regional Travel. Tourism Overview(Industry), 2012(03).

[4] L. Zheng. The Development of Tourism Electronic Commerce in Our Country and the Analysis on its Critical Limit Factors. Revolution and Strategy, 2009(07). 